\title{
A closed system irrigation \& drainage technique for surgical evacuation of chronic subdural haematomas [version 1; peer
}

\section{review: 3 approved]}

\author{
Haider Kareem (D1,2, Hadie Adams ${ }^{1,2}$ \\ ${ }^{1}$ Department of Neurosurgery, Charing Cross Hospital, Imperial College Healthcare NHS Trust, London, UK \\ 2Department of Neurosurgery, St Mary's Hospital, Imperial College Healthcare NHS Trust, London, UK
}

\author{
V1 First published: 21 May 2018, 7:619 \\ https://doi.org/10.12688/f1000research.14932.1 \\ Latest published: 21 May 2018, 7:619 \\ https://doi.org/10.12688/f1000research.14932.1
}

\section{Abstract}

Background: Chronic subdural haematoma (CSDH), is a common neurosurgical disorder that is associated with morbidity and mortality affecting the ageing population. The aim is to present the treatment experience of CSDH patients treated with a technique that combines the classical single burr-hole irrigation and the continuous closed system drainage: The closed system irrigation \& drainage (CSID) technique.

Methods: The cases undergoing CSDH evacuation with the CSID method were captured over a 4-year period at a tertiary neurosurgical centre. The authors describe the performance of this methods with respect to post-operative clinical and radiological features, including recurrence rates, complications, and length of stay.

Results: A total of 36 cases undergoing 42 CSID procedures (30 unilateral and 6 bilateral CSDHs) were performed, in cases ranging between 55-95 years old (median age 79 years). The rate of recurrence or significant ruminant blood in the subdural space on post-operative imaging was $11 \%(n=4)$. No cases of pneumocephalus were observed in this series $(n=0)$. The mean (SD) skin-to-skin time for this procedure was 13.4 (4.4) minutes, with a mean (SD) length of stay of 4 (1.9) days. Conclusion: We conclude that the one burr-hole closed system irrigation and drainage technique with a sub-periosteal drain seems to be a simple, effective and safe procedure for treatment of CSDH. It's well tolerated under local anaesthesia for patients with high comorbidities and these preliminary results indicated it may potentially be a better option for treatment of CSDH with a lower rate of postoperative complications.

\section{Keywords}

Chronic Subdural Heamatoma, Sub-periosteal drain, Close System Irrigation and Drainage (CSID), Single Burr-Hole

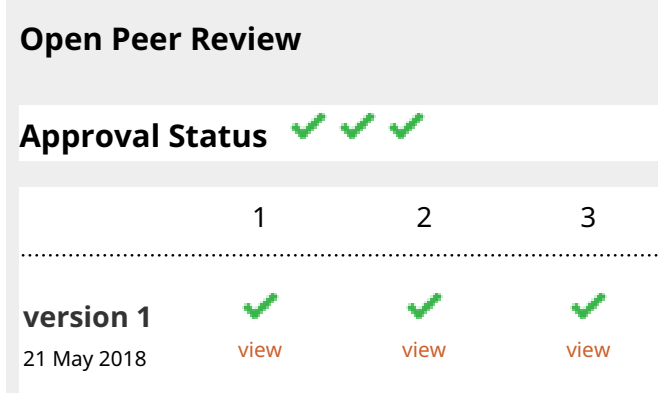

1. Matthew A. Kirkman (D), The National Hospital for Neurology and Neurosurgery, University College London Hospital NHS Foundation Trust, London, UK

2. Richard Z. Fu, Manchester Centre for Clinical Neurosciences, Greater Manchester, UK

3. Rafid Al-mahfoudh, Brighton and Sussex University Hospital NHS Trust, Brighton, UK Any reports and responses or comments on the article can be found at the end of the article. 
Corresponding author: Haider Kareem (haider.kareem@nhs.net)

Author roles: Kareem H: Conceptualization, Data Curation, Formal Analysis, Investigation, Methodology, Project Administration, Resources, Supervision, Writing - Original Draft Preparation; Adams H: Validation, Visualization, Writing - Review \& Editing

Competing interests: No competing interests were disclosed.

Grant information: The author(s) declared that no grants were involved in supporting this work.

Copyright: @ 2018 Kareem $\mathrm{H}$ and Adams $\mathrm{H}$. This is an open access article distributed under the terms of the Creative Commons Attribution License, which permits unrestricted use, distribution, and reproduction in any medium, provided the original work is properly cited.

How to cite this article: Kareem $\mathrm{H}$ and Adams $\mathrm{H}$. A closed system irrigation \& drainage technique for surgical evacuation of chronic subdural haematomas [version 1; peer review: 3 approved] F1000Research 2018, 7:619

https://doi.org/10.12688/f1000research.14932.1

First published: 21 May 2018, 7:619 https://doi.org/10.12688/f1000research.14932.1 


\section{Introduction}

Chronic subdural haematoma (CSDH), is a common neurosurgical disorder that is associated with high morbidity and mortality affecting the ageing population. The projected ageing of the population, and the steady increase in the use of anti-platelets and anticoagulants in modern preventive medicine, will expectedly lead to a rising incidence of anticoagulant-related complications, including $\mathrm{CSDH}^{1}$. Its incidence is about (5 per 100000 per year) in the general population, but is higher for those aged 70 years and older (58 per 100000 per year) ${ }^{2}$. The three most common described surgical techniques for subdural hematoma evacuation are: craniotomy, burr hole trephination, and twist-drill trephination ${ }^{3}$. A randomised controlled trial by Santarius et al. in 2009 concluded that placement of a subdural drain after burr-hole evacuation of CSDH was associated with reduced recurrence rate. Recent studies reported that there are no significant differences in post-operative complication and mortality rate between the type of drain used, whether subperiosteal or subdural drain ${ }^{4-6}$. In addition to the risk of recurrence, one of the common immediate post-operative complications is pneumocephalus, CSDHs are commonly associated with cerebral atrophy and the associated increase in potential dead space in the subdural area. This factor, in addition to head positioning of the patient's head during surgery in a neutral supine or slightly tilt, can lead to air collecting at the frontal pole of the subdural space. This can range from simple benign pneumocephalus to tension pneumocephalus with significant morbidity and mortality 7,8 .

We present a prospectively collected case series to present a simple surgical technique in the treatment of a common neurosurgical condition, patients presenting with a CSDH requiring surgical evacuation. This technique combines the classical burr-hole irrigation technique and the continuous closed system drainage technique by irrigating in a closed system with continues drainage: the closed system irrigation \& drainage (CSID) technique. The modified irrigation technique of this approach is to minimise the operative time, risk of recurrence, and the risk of post-operative pneumocephalus. This study reflects a single surgeon's experience in the treatment of this condition with cases treated and followed-up over a period of 4 years. We believe that this procedure has proven to be simple, effective, with a relatively short operative time and a low risk of intra- and post-operative complications. Given that the procedure can effectively be done with a single burr hole trephination, we believe that this procedure is easily tolerated under local anaesthesia which is suitable in the treatment of elderly patients with high comorbidities and those unlikely to tolerate general anaesthesia which is common amongst the population presenting with this neurosurgical disorder.

\section{Methods}

This case series involves data collected at pre-intervention and post-intervention within routine clinical practice. The UK National Health Service National Research Ethics Service guidance on such research (National Health Service Health Research Authority, 2011 $)^{9}$ determined that the study did not require ethical appraisal or clearance, as it was an evaluation of routine practice/National Health Service audit. Pictures and video recording of the intraoperative surgical procedure were used, alongside pre- and post-operative CT images of the same case for which informed written consent was obtained.

In this prospective cohort, we aimed to present the data of 36 consecutive patients who underwent surgery for symptomatic chronic subdural hematomas from 2014 to 2018 by a single surgeon (H.K.) at the Imperial College London NHS Trust (locations: Charing Cross Hospital and St Mary's Hospital). Data from a total of 36 patients receiving 42 procedures are presented in this series. General patient data, including age, sex, secondary diagnosis, drug history, and other risk factors, as well as preoperative symptoms, Glasgow Coma Scale (GCS) at admission, and findings of preoperative Computed Tomography (CT) studies were collected. The side of the haematoma (right, left or bilateral), postoperative symptoms, findings of postoperative CT scan, complications, the rate of recurrence or remnant hematoma were also captured. All patients underwent single-hole trepanation, intraoperative Jacques catheter irrigation, and placement of subperiosteal closed drainage system as the first surgical treatment.

\section{Operative technique}

Prior to surgery, all patients received full clinical assessment and workup, including reversal of anticoagulation if applicable and consented/assented according to the local protocols for the procedure. One dose of prophylactic antibiotic is usually given at the time of skin incision. The patient is positioned supine or slight lateral position by insertion of gel pads or sandbags under the shoulder and pelvis ipsilateral to the side of haematoma (Figure 1A \& 1B). In case of bilateral CSDH, each side is done separately. The head of the patients is tilted to the opposite side. After skin preparation, marking the site of trepanation is at the maximum thickness of the haematoma, which should be the most superior part of the head and parallel to the floor, to avoid air entrapment in the subdural space. A mixed long and short-acting local anaesthetic agent is injected into the incision site, the drain exits and drain's stitching point, which is usually generously infiltrated especially in the local anaesthetics cases (Figure 2). A skin incision is made about $5 \mathrm{~cm}$ long, followed by meticulous haemostasis of the skin edge to prevent tracking of fresh blood from the skin to the subdural space at the later stage of the procedure. Following dissection of the periosteum, a self-retaining retractor is then inserted, we usually make sure that there is no bleeding from the edges of the skin or any other point before retractor inserted. Periosteal elevation and burr hole fenestration of the skull is subsequently undertaken, haemostasis of the bone edge and bipolar diathermy of the dura matter preparing for dural opening (Figure 3). The dura is opened in a cruciate fashion with complete cauterisation of the edges to ensure dural retraction and creating small dural defect equivalent to the osseous fenestration. At this stage, the blood starts draining from the subdural space. We make sure to fenestrate any visible membrane over the surface of the brain until the brain is visible without chasing the membrane beyond the dural defect to avoid bleeding from a remote area of the subdural space. The tip of Jacques catheter is then inserted into the subdural space for few millimetre and size 10 subperiosteal closed gravity drain inserted 


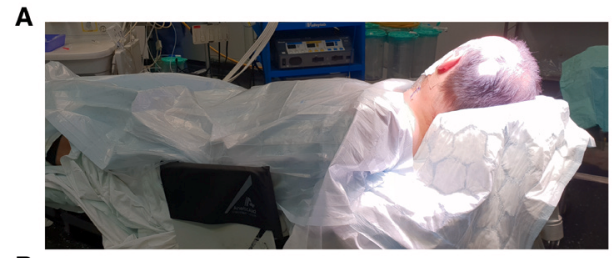

B

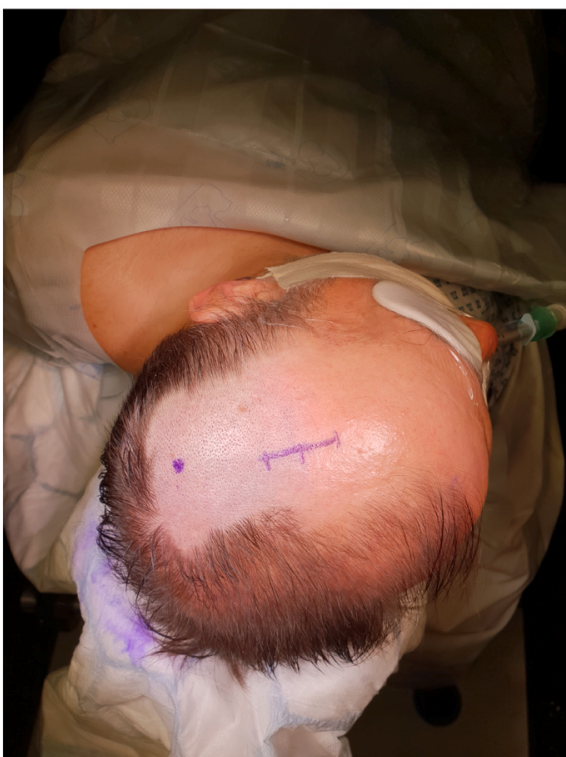

Figure 1. A) The patient is positioned slight lateral position by insertion of gel pads or sandbags under the shoulder and pelvis ipsilateral to the side of haematoma. B) Marking of skin incision and drain's exit point.

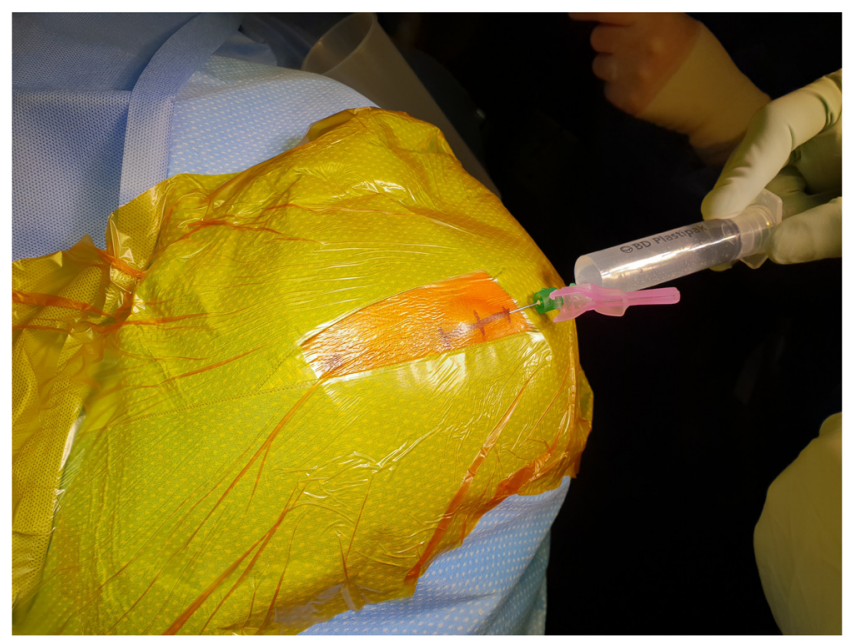

Figure 2. A mixed long and short-acting local anaesthetic agent is injected into the incision site, the drain exits and drain's stitching point.

and tunnelled at least 5-7 cm from the surgical site. At this stage, we make sure that the fenestrated part of the sub-periosteal drain is overlying the osseous and dural defect (Figure 4). The Jacques catheter remains at the anterior end of the surgical wound, we remove the retractor and start repairing the galea with vicryl sutures, followed by skin closure around the Jacques catheter (Figure 5). The subdural collection then washed out with warm Ringer's lactate saline with a $50 \mathrm{~mL}$ syringe connected Jacques catheter. Irrigating fluid will run to the subdural space through the tip of the Jacques catheter, circulate through subdural space, irrigating all the blood and air from the subdural space and collected through the sub-periosteal drain. The process of slow irrigation continues until the outcoming irrigation fluid becomes clear. When the procedure is under local anaesthesia, we ask the patient, with anaesthetic help, to move the head from one side to another slowly which help in clearing the air and remaining blood in the subdural space. Once the irrigation fluid is clear, we

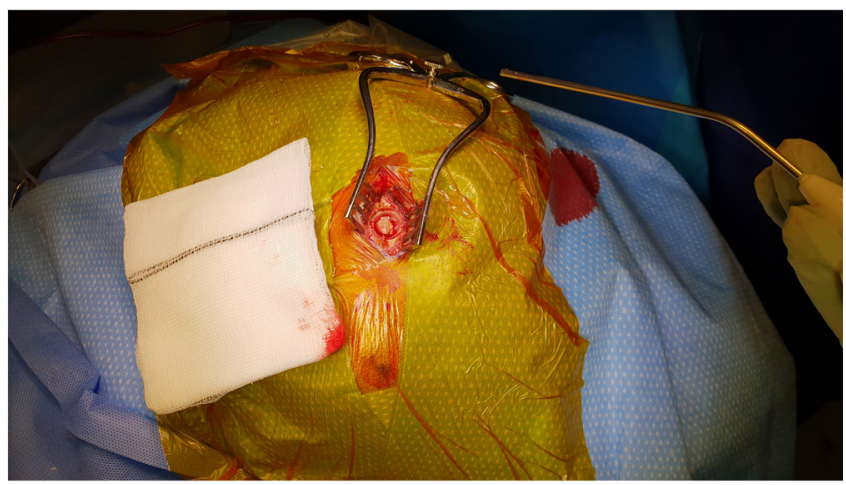

Figure 3. Periosteal elevation and burr hole fenestration of the skull. Prior to dural opening haemostasis of the bone edge and bipolar diathermy of the dura matter is undertaken.

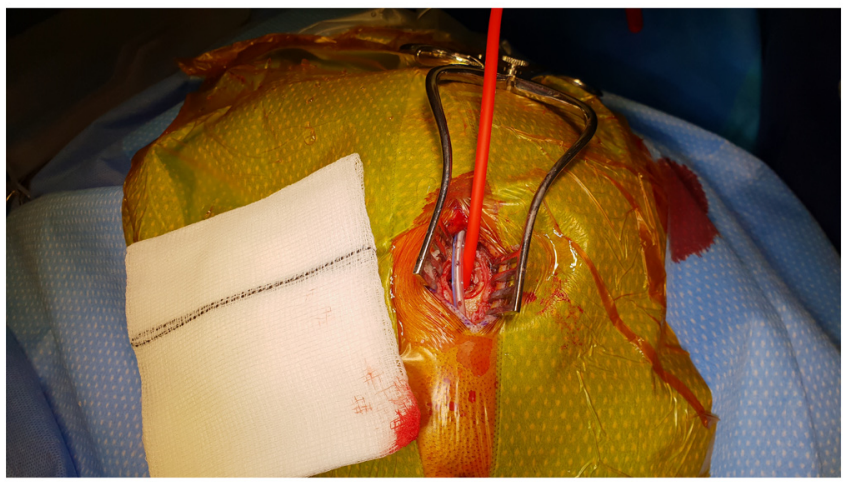

Figure 4. Jacques catheter and subperiosteal drain orientation at the surgical site.

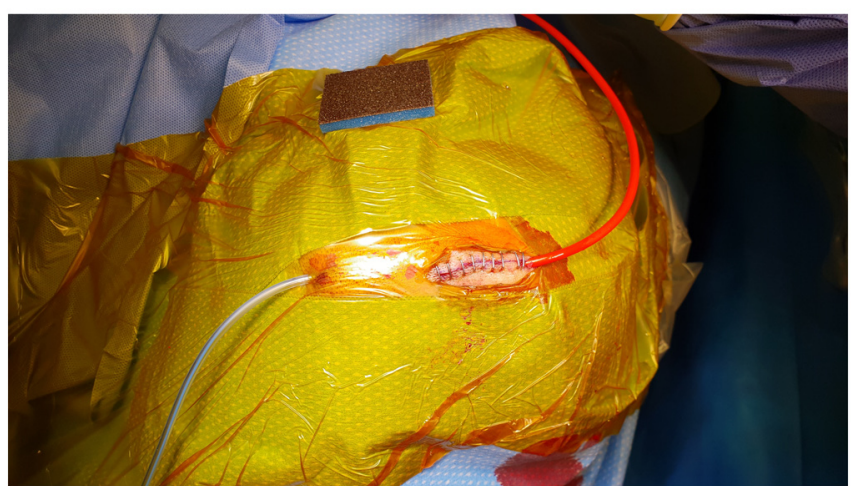

Figure 5. Skin closure around the Jacques catheter. 
pulled the Jacques catheter from the wound and suture or staple the remaining small opening in the incision (Figure 6). The sub-periosteal drain is usually kept in for 24-48 hours to collect all the subdural ruminant fluid and blood which is further aided by the brain pulsation. In case of bilateral CSDHs, similar steps are then followed on the other side. A video of the procedure is available as part of the supplementary material (Supplementary Video 1). Post-operative CT scan images of the same patient are demonstrated in Figure 7A and 7B.

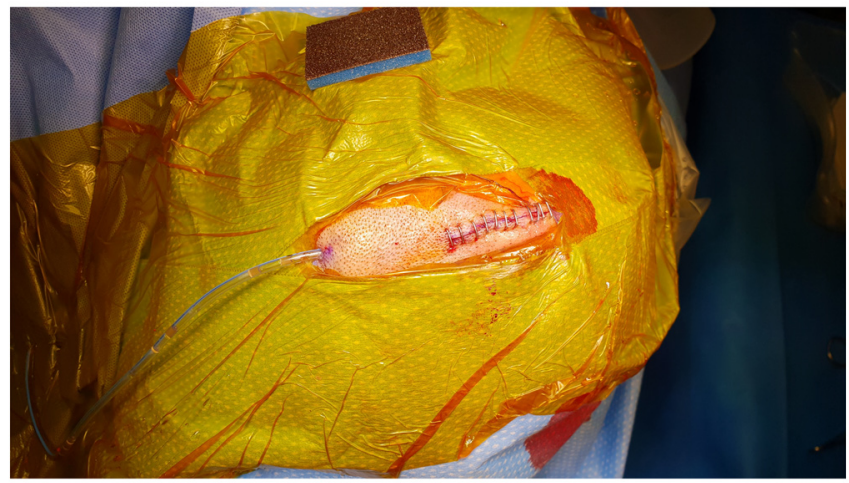

Figure 6. Jacques catheter removed from the wound and suture or staple of the remaining small opening in the incision.

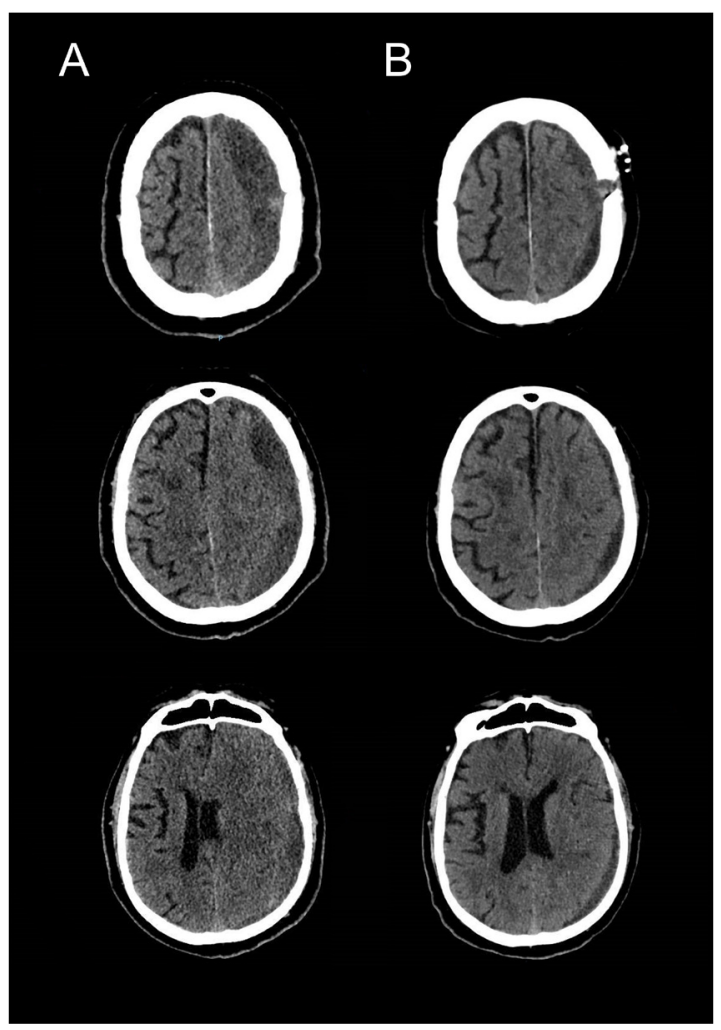

Figure 7. Pre- (A) \& post-operative (B) [Day 2] cranial CT-scans demonstrating satisfactory evacuation of the subdural collection and expansion of the brain parenchyma with no pneumocephalus in the subdural space.

\section{Results}

A total of 36 patients, including $26(72.2 \%)$ males and $10(27.8)$ females underwent 42 surgical procedures (30 patients unilateral and 6 patients with bilateral trephination). The age ranges from 55-95 years old with median age 79 years (IQR 14). A total of 20 patients underwent right side surgery, 10 patient left side surgery and 6 patients underwent bilateral trephination. The vast majority, 34 (94.4\%) patients had a history of trauma, mainly frequent falls. Two patients had no history of trauma reported by the patients, relatives or carer. Seven $(19.4 \%)$ patients were on anticoagulation treatment, $13(36 \%)$ patients were on antiplatelet and $4(11 \%)$ patients were on both (Table 1$)$.

The most common clinical features on admission were hemiparesis $(n=26,72 \%)$, decreased level of consciousness with a GCS $<13 / 15(n=19,52.7 \%)$, headache $(n=18,50 \%)$, confusion $(n=11,30.5 \%)$, dysphasia $(n=2,5.5 \%)$ and seizures $(n=1,2.7 \%)$.

Table 1. Baseline characteristics in $\mathbf{3 6}$ patients treated with the CSID method.

\begin{tabular}{|c|c|}
\hline Variables & $\mathbf{N}(\%)$ \\
\hline Total Number of patients & 36 \\
\hline Median (IQR) Age in years & $79(14)$ \\
\hline Sex, male & $26(72.2 \%)$ \\
\hline $\begin{array}{l}\text { Laterality } \\
\text { Left-sided subdural hematoma } \\
\text { Right-sided subdural hematoma } \\
\text { Bilateral subdural hematoma }\end{array}$ & $\begin{array}{l}20(55.5 \%) \\
10(27.7 \%) \\
6(16.6 \%)\end{array}$ \\
\hline $\begin{array}{l}\text { Clinical Presentation } \\
\text { Confusion } \\
\text { Headache } \\
\text { Hemiparesis } \\
\text { Dysphasia } \\
\text { Seizure }\end{array}$ & $\begin{array}{l}11(30.5 \%) \\
18(50.0 \%) \\
26(72.0 \%) \\
1(5.5 \%) \\
1(2.7)\end{array}$ \\
\hline $\begin{array}{l}\text { Anti-clotting agents } \\
\text { On anticoagulation } \\
\text { On antiplatelet medication }\end{array}$ & $\begin{array}{l}7(19.4 \%) \\
13(36.0 \%)\end{array}$ \\
\hline $\begin{array}{l}\text { Co-morbid conditions } \\
\text { Hypertension } \\
\text { Diabetes Mellitus } \\
\text { Ischaemic heart disease } \\
\text { Dementia } \\
\text { Arrhythmia } \\
\text { Cerebrovascular accident } \\
\text { Seizure } \\
\text { Superficial wound infection }\end{array}$ & $\begin{array}{l}14(38.8 \%) \\
10(27.7 \%) \\
7(19.5 \%) \\
2(5.5 \%) \\
6(16.5 \%) \\
3(8.3 \%) \\
1(2.7 \%) \\
1(2.7 \%)\end{array}$ \\
\hline $\begin{array}{l}\text { Glasgow coma scale } \\
\begin{array}{l}3-8 \\
9-12 \\
13-15\end{array}\end{array}$ & $\begin{array}{l}4(11.0 \%) \\
11(30.5 \%) \\
21(58.3 \%)\end{array}$ \\
\hline
\end{tabular}

Skin to skin time in minutes (mean \pm SD) 13.4 (4.4) 
All patients were re-examined post-operatively with regard to presenting symptoms. Post-operative cranial imaging (CT-scan) was done routinely $24-48$ hours after the operation as a baseline investigation and also to exclude remnant haematoma or pneumocephalus (Figure 7A \& 7B), CT imaging was also performed on clinical follow-up after 1-3 months if indicated. Postoperative pneumocephalus was excluded in all patients. Symptomatic haematoma recurrence developed in 4 patients $(11 \%), 2$ of them underwent re-operation in form of minicraniotomy with excision of the membranes in multi-layered CSDHs. The other 2 patients were treated conservatively as they were not fit for general anaesthesia. Five patients whose CT scan showed a small residual haematoma, but without any neurological deficit, were followed up with satisfactory longterm resolution of the pre-operative symptoms. Postoperative complications developed in 3 patients, one patient suffered partial motor seizures that were managed successfully with anticonvulsant drugs, the two other patients suffered from pneumonia. The mean (SD) length of stay in the neurosurgical unit up until repatriation to secondary care was 4 (1.9) days (Table 2). Further post-operative events, including complications, are summarised in Table 2.

\section{Discussion}

Although there is a wide range of opinions about the proper surgical management of this common neurosurgical condition, a scoping literature review shows no significant differences in mortality or complications rates between different surgical techniques, and complication rates of the closed draining sys-

Table 2. Post-operative events in $\mathbf{3 6}$ patients treated with the CSID methods.

\begin{tabular}{|l|l|}
\hline Post-operative events & N (\%) \\
\hline $\begin{array}{l}\text { Post-operative Glasgow Coma scale } \\
\text { 3-8 } \\
9-12 \\
13-15\end{array}$ & $0(0.0 \%)$ \\
\hline Symptomatic residual haematoma & $3(8.3 \%)$ \\
\hline Craniotomy needed & $33(91.7)$ \\
\hline Contralateral haematoma & $4(11.0 \%)$ \\
\hline Pneumocephalus & $2(5.5 \%)$ \\
\hline Subdural infection & $0(0.0 \%)$ \\
\hline Wound infection & $0(0.0 \%)$ \\
\hline Pneumonia & $0(0.0 \%)$ \\
\hline Deep venous thrombosis & $1(2.7 \%)$ \\
\hline Other medical complications & $2(5.5 \%)$ \\
\hline $\begin{array}{l}\text { Cardiac arrhythmia } \\
\text { Pevere vertigo and dizziness }\end{array}$ & $1(2.7 \%)$ \\
\hline $\begin{array}{l}\text { Severe uncontrollable hypertension } \\
\text { Mortality during admission to Neurosurgical Unit }\end{array}$ & $0(0.0 \%)$ \\
\hline Length of stay in days (mean \pm SD) & $2(5.5 \%)$ \\
\hline
\end{tabular}

tem after subdural irrigation seems to be similar to the tradition burr-hole irrigation of the subdural space. In addition to that, there were no obvious differences in recurrence between irrigation and no irrigation. However, using a closed drain system seems to be associated with a reduction of the recurrence rate of subdural collection in compare with burr-hole evacuation only ${ }^{2,10,11}$. In 2009, Zumofen et al. published the first series of patients treated with placement of a sub-periosteal drain system instead of the widely used subdural drain system after double burr-hole craniotomy for hematoma evacuation. They reported equal-to-superior results compared with previous studies regarding hematoma recurrence, mortality, and serious complications, especially postoperative seizures ${ }^{12}$.

There is evidence in the literature suggest that sudden evacuation of chronic subdural hematoma may lead to growth or development of remote (contralateral) subdural, epidural or intracerebral haematomas ${ }^{13-17}$. The possible mechanisms behind this phenomenon include the rapid shift of the cerebral hemisphere following hematoma evacuation, over drainage of the subdural space, and cerebral hyperperfusion syndrome, although the actual pathophysiology behind this process remains unclear ${ }^{16-20}$. We suggest that the CSID technique will allow for a gradual, and physiological more natural, expansion of the brain during the irrigation and drainage process. Unlike the classical burr-hole irrigation technique, with the CSID method, the subdural collection will be slowly substituted with irrigation fluid in a closed system. Similar to the continuous closed system drainage techniques, the CSID method will also allow continues drainage without the introduction of air in the subdural space or rapid shift, however, it also offers the advantages of thorough irrigation. The cerebral pulsations will allow for a slow expansion of the brain parenchyma and a gentler expulsion of the irrigation fluid and possible remaining blood products in the subdural space through the indolent subperiosteal drain.

It has been widely described that air in the subdural space can physically block re-expansion of the brain following the evacuation of a CSDH. It has also been demonstrated that pneumocephalus increases the recurrence rate of chronic subdural haematomas, and prolongs the hospital stay and healing time ${ }^{21}$. In the present cohort, no cases of (symptomatic) pneumocephalus were observed, given that post-operative symptomatic pneumocephalus was reported as relatively common complication in the literature, with $8 \%$ of the cases undergoing burr-hole irrigation procedures are followed by tension pneumocephalus ${ }^{22-24}$.

The rate of recurrence or significant ruminant blood in the subdural space on post-operative imaging was $11 \%$ (4 patients). Surgical intervention in the form of a mini-craniotomy was needed in 2 patients. Intra-operatively these cases showed multilayered membrane adhesions to the surface of the brain. The other 2 patients with symptomatic recurrence were treated conservatively as they were not appropriate candidates for general anaesthesia to undergo a mini-craniotomy due to other significant comorbidities. We didn't think that they would benefit from revision burr hole evacuation under local anaesthesia due to thick membrane obvious in their CT scan and failure of the first 
attempt to achieve the target. Reviewing the available literature, re-intervention rates after burr hole surgery with subdural drains vary between $8.3 \%$ and $30 \%{ }^{3,25-29}$, with our results falling within this range.

Post-operative infection is an uncommon complication after surgical evacuation of $\mathrm{CSDH}$, with postoperative empyema being reported to occur in approximately $2 \%$ of patients using burr-hole evacuation with or without subdural drain methods ${ }^{30,31}$. We didn't observe any deep tissue infection. One diabetic patient developed a superficial skin infection which responded well to oral antibiotic treatment.

The main limitation of this study was its small sample size. Despite including cases from a period of 4 years, the sample size of the final cohort was relatively small given it was a single centre and single surgeons experience, which can all introduce bias to our results. Whether this study lacked the adequate sample size to detect a significant difference between the presented cohort and the numbers presented in the literature or whether the results were indeed comparable remains a question. Another limitation is the inability to test risk factors that could have had an impact on recurrence or other post-operative complications. Also, it was difficult to evaluate its performance in patients with bilateral CSDHs because of the small number of patients with bilateral collections.

\section{Conclusion}

One burr-hole closed irrigation and drainage technique with a sub-periosteal drain seems to be a simple, effective and safe procedure for treatment of CSDH. It's well tolerated under local anaesthesia for patients with high co-morbidities and with a low rate of post-operative complication. Larger series are needed to directly compare this technique's long-term performance to other established methods, however, these preliminary results indicated it may potentially be a better option for treatment of CSDH with a lower rate of post-operative complications.

\section{Data availability}

Data cannot be shared because the routinely collected patient data used in the study belong to the Imperial College London and Imperial College Healthcare NHS Trust and not the authors. Researchers can apply to access the data through the Trust's R\&D Department at jrco@imperial.ac.uk.

\section{Competing interests}

No competing interests were disclosed

\section{Grant information}

The author(s) declared that no grants were involved in supporting this work

\section{Supplementary material}

Supplementary Video 1 - A step-by-step video demonstrating the closed system irrigation \& drainage technique for surgical evacuation of chronic subdural haematomas.

Click here to access the data.

1. Mckissock W, Richardson A, Bloom WH: Subdural heamatoma: a review of $\mathbf{3 8 9}$ cases. Lancet. 1960; 275(7139): 4.

2. Santarius T, Kirkpatrick PJ, Ganesan D, et al.: Use of drains versus no drains after burr-hole evacuation of chronic subdural haematoma: a randomised controlled trial. Lancet. 2009; 374(9695): 1067-73. PubMed Abstract | Publisher Full Text

3. Weigel R, Schmiedek P, Krauss JK: Outcome of contemporary surgery for chronic subdural haematoma: evidence based review. J Neurol Neurosurg Psychiatry. 2003; 74(7): 937-43.

PubMed Abstract | Publisher Full Text | Free Full Text

4. Bellut D, Woernle CM, Burkhardt JK, et al:: Subdural drainage versus subperiosteal drainage in burr-hole trepanation for symptomatic chronic subdural hematomas. World Neurosurg. 2012; 77(1): 111-8. PubMed Abstract | Publisher Full Text

5. Chih AN, Hieng AW, Rahman NA, et al:: Subperiosteal Drainage versus Subdural Drainage in the management of Chronic Subdural Hematoma (A Comparative Study). Malays J Med Sci. 2017; 24(1): 21-30. PubMed Abstract | Publisher Full Text | Free Full Text

6. Gazzeri R, Galarza M, Neroni M, et al:: Continuous subgaleal suction drainage for the treatment of chronic subdural haematoma. Acta Neurochir (Wien). 2007; 149(5): 487-93; discussion 493. PubMed Abstract | Publisher Full Text
7. Miele VJ, Sadrolhefazi A, Bailes JE: Influence of head position on the effectiveness of twist drill craniostomy for chronic subdural hematoma. Surg Neurol. 2005; 63(5): 420-3; discussion 423. PubMed Abstract | Publisher Full Text

8. Schirmer CM, Heilman CB, Bhardwaj A: Pneumocephalus: case illustrations and review. Neurocrit Care. 2010; 13(1): 152-8. PubMed Abstract | Publisher Full Text

9. Authority NHSHR: Does my project require review by a Research Ethics Committee? 2011. Reference Source

10. Xu C, Chen S, Yuan L, et al.: Burr-hole Irrigation with Closed-system Drainage for the Treatment of Chronic Subdural Hematoma: A Meta-analysis. Neurol Med Chir (Tokyo). 2016; 56(2): 62-8. PubMed Abstract | Publisher Full Text | Free Full Text

11. Lind CR, Lind CJ, Mee EW: Reduction in the number of repeated operations for the treatment of subacute and chronic subdural hematomas by placement of subdural drains. J Neurosurg. 2003; 99(1): 44-6. PubMled Abstract | Publisher Full Text

12. Zumofen $\mathrm{D}$, Regli L, Levivier M, et al.: Chronic subdural hematomas treated by burr hole trepanation and a subperiostal drainage system. Neurosurgery. 2009; 64(6): 1116-21; discussion 1121-2. PubMed Abstract | Publisher Full Text 
13. Panourias IG, Skandalakis PN: Contralateral acute epidural haematoma following evacuation of a chronic subdural haematoma with burr-hole craniostomy and continuous closed system drainage: a rare complication. Clin Neurol Neurosurg. 2006; 108(4): 396-9.

PubMed Abstract | Publisher Full Text

14. Sun HL, Chang CJ, Hsieh CT: Contralateral acute subdural hematoma occurring after evacuation of subdural hematoma with coexistent contralateral subdural hygroma. Neurosciences (Riyadh). 2014; 19(3): 229-32.

PubMed Abstract | Free Full Text

15. Eom KS, Kim TY, Park JT: Contralateral acute interdural haematoma occurring after burr hole drainage of chronic subdural haematoma. Br J Neurosurg. 2009; 23(2): 213-5.

PubMed Abstract | Publisher Full Text

16. Cohen-Gadol AA: Remote contralateral intraparenchymal hemorrhage after overdrainage of a chronic subdural hematoma. Int J Surg Case Rep. 2013; 4(10): 834-6.

PubMed Abstract | Publisher Full Text | Free Full Text

17. $\mathrm{Kim} \mathrm{CH}$, Song GS, Kim YH, et al:: Remote Hemorrhage after Burr Hole Drainage of Chronic Subdural Hematoma. Korean J Neurotrauma. 2017; 13(2): 144-148.

PubMed Abstract | Publisher Full Text | Free Full Text

18. Gürbüz MS, Karaarslan N, Gök S, et al:: Remote Cerebellar Haemorrhage after Burr Hole Drainage of Chronic Subdural Haematoma: A Case Report. J Clin Diagn Res. 2016; 10(5): PD01-2.

PubMed Abstract | Publisher Full Text | Free Full Text

19. Kobayashi $\mathrm{S}$, Mutoh $\mathrm{T}$, Ishikaw $\mathrm{T}$, et al.: [Remote cerebellar hemorrhage after single burr hole drainage of chronic subdural hematoma of the elderly]. No Shinkei Geka. 2011; 39(8): 755-61.

PubMed Abstract | Publisher Full Text

20. Wang G, Yu J: Remote acute subarachnoid hemorrhage after drainage of chronic subdural hematoma: A case report and review of the literature. Int $J$ Surg Case Rep. 2018; 44: 202-206.

PubMed Abstract | Publisher Full Text | Free Full Text

21. You CG, Zheng XS: Postoperative pneumocephalus increases the recurrence rate of chronic subdural hematoma. Clin Neurol Neurosurg. 2018; 166: 56-60. PubMed Abstract | Publisher Full Text
22. Sharma BS, Tewari MK, Khosla VK, et al:: Tension pneumocephalus following evacuation of chronic subdural haematoma. Br J Neurosurg. 1989; 3(3): 381-7. PubMed Abstract | Publisher Full Text

23. Mori K, Maeda M: Surgical treatment of chronic subdural hematoma in $\mathbf{5 0 0}$ consecutive cases: clinical characteristics, surgical outcome, complications, and recurrence rate. Neurol Med Chir (Tokyo). 2001; 41(8): 371-81. PubMed Abstract | Publisher Full Text

24. Kravtchouk AD, Likhterman LB, Potapov AA, et al:: Postoperative complications of chronic subdural hematomas: prevention and treatment. Neurosurg Clin N Am. 2000; 11(3): 547-52. PubMed Abstract

25. Wakai S, Hashimoto K, Watanabe N, et al:: Efficacy of closed-system drainage in treating chronic subdural hematoma: a prospective comparative study. Neurosurgery. 1990; 26(5): 771-3. PubMed Abstract | Publisher Full Tex

26. Matsumoto K, Akagi K, Abekura M, et al.: Recurrence factors for chronic subdural hematomas after burr-hole craniostomy and closed system drainage. Neurol Res. 1999; 21(3): 277-80. PubMed Abstract | Publisher Full Text

27. Kotwica Z, Brzeziński J: Chronic subdural haematoma treated by burr holes and closed system drainage: personal experience in 131 patients. $\mathrm{Br} J$ Neurosurg. 1991; 5(5): 461-5

PubMed Abstract | Publisher Full Text

28. Ernestus $\mathrm{RI}$, Beldzinski $\mathrm{P}$, Lanfermann $\mathrm{H}$, et al:: Chronic subdural hematoma: surgical treatment and outcome in 104 patients. Surg Neurol. 1997; 48(3): 220-5. PubMed Abstract | Publisher Full Text

29. El-Kadi H, Miele VJ, Kaufman $\mathrm{HH}$ : Prognosis of chronic subdural hematomas. Neurosurg Clin N Am. 2000; 11(3): 553-67. PubMed Abstract

30. Rohde V, Graf G, Hassler W: Complications of burr-hole craniostomy and closed-system drainage for chronic subdural hematomas: a retrospective analysis of $\mathbf{3 7 6}$ patients. Neurosurg Rev. 2002; 25(1-2): 89-94. PubMed Abstract | Publisher Full Text

31. Pencalet $P$ : [Complications of chronic subdural hematoma in the adult]. Neurochirurgie. 2001; 47(5): 491-4.

PubMed Abstract 


\section{Open Peer Review}

\section{Current Peer Review Status:}

\section{Version 1}

Reviewer Report 29 May 2018

https://doi.org/10.5256/f1000research.16257.r34257

(C) 2018 Al-mahfoudh R. This is an open access peer review report distributed under the terms of the Creative Commons Attribution License, which permits unrestricted use, distribution, and reproduction in any medium, provided the original work is properly cited.

\section{Rafid Al-mahfoudh}

Brighton and Sussex University Hospital NHS Trust, Brighton, UK

This report on treatment of chronic subdural haematomas with a closed irrigation / drainage system is a good pilot for a larger study to compare the methods used. Allowing a more accurate assessment of any potential benefits compared to the more standard treatment methods especially for outcomes such as recurrence.

Please clarify if the irrigation through the Jacques catheter was performed intraoperatively only or if it was continued postoperatively (if so then give an indication how long this was for).

Otherwise this is a well written article which I recommend for indexing.

Is the background of the cases' history and progression described in sufficient detail? Yes

Are enough details provided of any physical examination and diagnostic tests, treatment given and outcomes?

Yes

Is sufficient discussion included of the importance of the findings and their relevance to future understanding of disease processes, diagnosis or treatment?

Yes

Is the conclusion balanced and justified on the basis of the findings?

Yes

Competing Interests: No competing interests were disclosed.

I confirm that I have read this submission and believe that I have an appropriate level of 
expertise to confirm that it is of an acceptable scientific standard.

Reviewer Report 25 May 2018

https://doi.org/10.5256/f1000research.16257.r34255

(c) $2018 \mathrm{Fu}$ R. This is an open access peer review report distributed under the terms of the Creative Commons Attribution License, which permits unrestricted use, distribution, and reproduction in any medium, provided the original work is properly cited.

Richard Z. Fu

Department of Neurosurgery, Manchester Centre for Clinical Neurosciences, Greater Manchester, UK

This paper by authors Kareem $\mathrm{H}$ and Adams $\mathrm{H}$ presents an interesting prospective case series of patients who received an operation for the diagnosis of chronic subdural haematoma which utilised a novel yet seemingly simple, close system irrigation and drainage technique.

Their results show a recurrence rate not notably different from that reported in the wider literature. Their result of no pneumocephalus reported in their case series is perhaps the most interesting result. Additionally, they report a short operating time and hospital stay which might represent a potential economic benefit to the health service.

It would have been of value to note the clinical course of other patients in the unit who underwent a more standard operative intervention during the same time period, and for this to have been compared.

Their paper provides a relevant and helpful review of the existing literature. Their conclusions drawn are measured and balanced, with dutiful awareness of the study's limitations.

Their results could pave the way for a meaningful larger study to follow, where rates of recurrence, pneumocephalus and the cost benefit ratio of operating time and hospital stay can be further explored.

Is the background of the cases' history and progression described in sufficient detail? Yes

Are enough details provided of any physical examination and diagnostic tests, treatment given and outcomes?

Yes

Is sufficient discussion included of the importance of the findings and their relevance to future understanding of disease processes, diagnosis or treatment?

Yes

Is the conclusion balanced and justified on the basis of the findings? 
Yes

Competing Interests: No competing interests were disclosed.

I confirm that I have read this submission and believe that I have an appropriate level of expertise to confirm that it is of an acceptable scientific standard.

Reviewer Report 23 May 2018

https://doi.org/10.5256/f1000research.16257.r34256

(C) 2018 Kirkman M. This is an open access peer review report distributed under the terms of the Creative Commons Attribution License, which permits unrestricted use, distribution, and reproduction in any medium, provided the original work is properly cited.

\section{Matthew A. Kirkman}

Victor Horsley Department of Neurosurgery, The National Hospital for Neurology and Neurosurgery, University College London Hospital NHS Foundation Trust, London, UK

This is a prospective study of 36 consecutive patients with chronic subdural haematoma presenting to a single tertiary UK neurosurgical centre over a 4-year period. The authors evaluated use of the so-called closed system irrigation and drainage (CSID) technique, finding no patients developed pneumocephalus, although recurrence or significant residual blood was seen in $11 \%$. Skin-to-skin time was short (mean 13.4 minutes), and mean length of stay in the neurosurgical unit was 4 days.

This is an interesting study of a common condition seen in neurosurgical practice, and a useful addition to the literature. The multimedia included add significant value to the paper. The authors discuss the limitations of their study clearly. The data suggests that this technique warrants further study in a larger population. I have a couple of questions for the authors:

1. Do the authors have any comparative data from patients with CSDH treated at the same centre during the same time period, but with different surgical techniques e.g. standard burr-hole irrigation? It would be interesting to compare (perhaps even statistically) surgical time, complication rates and length of stay between the different approaches. However, I do note that the authors already quote previous literature when discussing the complication rates associated with other surgical approaches to $\mathrm{CSDH}$, which in itself is useful.

2. Table 1 indicates that one patient had a superficial wound infection in the "Co-morbid conditions" section - can the authors clarify exactly where this patient's infection was, and if it was the same patient that developed a wound infection after sutrgery (as per Table 2).

Is the background of the cases' history and progression described in sufficient detail? Yes

Are enough details provided of any physical examination and diagnostic tests, treatment 
given and outcomes?

Yes

Is sufficient discussion included of the importance of the findings and their relevance to future understanding of disease processes, diagnosis or treatment?

Yes

Is the conclusion balanced and justified on the basis of the findings?

Yes

Competing Interests: No competing interests were disclosed.

I confirm that I have read this submission and believe that I have an appropriate level of expertise to confirm that it is of an acceptable scientific standard.

The benefits of publishing with F1000Research:

- Your article is published within days, with no editorial bias

- You can publish traditional articles, null/negative results, case reports, data notes and more

- The peer review process is transparent and collaborative

- Your article is indexed in PubMed after passing peer review

- Dedicated customer support at every stage

For pre-submission enquiries, contact research@f1000.com 